\title{
Multi-scale research of time and space differences about ecological footprint and ecological carrying capacity of the water resources
}

\author{
Jiahong $\mathrm{Li}^{1} \cdot$ Xiaohui Lei ${ }^{2} \cdot$ Qiang $\mathrm{Fu}^{3} \cdot{\text { Tianxiao } \mathrm{Li}^{3} \cdot \mathrm{Yu} \mathrm{Qiao}^{4} \cdot \text { Lei Chen }^{5} \cdot \text { Weihong Liao }}^{2}$
}

Received: 4 October 2015 / Accepted: 28 December 2017 / Published online: 24 January 2018

(c) The Author(s) 2018. This article is an open access publication

\begin{abstract}
A multi-scale assessment framework for assessing and comparing the water resource sustainability based on the ecological footprint (EF) is introduced. The study aims to manage the water resource from different views in Heilongjiang Province. First of all, from the scale of each city, the water ecological carrying capacity (ECC) was calculated from 2000 to 2011, and map the spatial distribution of the recent 3 years which show that, the water ecological carrying capacity (ECC) is uneven and has a downward trend year by year. Then, from the perspective of the five secondary partition basins in Heilongjiang Province, the paper calculated the ecological carrying capacity (ECC), the ecological footprint (EF) and ecological surplus and deficit (S\&D) situation of water resources from 2000 to 2011, which show that the ecological deficit situation is more prominent in Nenjiang and Suifenhe basins which are in an unsustainable development state. Finally, from the perspective of the province, the paper calculated the ecological carrying capacity (ECC), the ecological footprint (EF) and ecological S\&D of water resources from 2000 to 2011 in Heilongjiang Province, which show that the ecological footprint (EF) is in the rising trend, and the correlation coefficient between the ecological carrying capacity (ECC) and the precipitation is 0.8 . There are 5 years of unsustainable development state in Heilongjiang. The proposed multi-scale assessment of WEF aims to evaluate the complex relationship between water resource supply and consumption in different spatial scales and time series. It also provides more reasonable assessment result which can be used by managers and regulators.
\end{abstract}

Keywords Multi-scale $\cdot$ Time and space differences · Water resources · Ecological footprint · Ecological carrying capacity · Sustainable development

\section{Introduction}

The concept and calculation method of EF was put forward by Canadian ecological economist William E. Rees (1992). The further development and improvement about calculation principles and methods are given by his student

Jiahong Li

liquanhui1992@163.com

1 School of Civil Engineering, Tianjin University, Tianjin, China

2 China Institute of Water Resources and Hydropower Research, Beijing, China

3 School of Water Conservancy and Civil Engineering, Northeast Agricultural University, Harbin, China

4 Construction and Administration Bureau of South-to-North Water Diversion Middle RouteProject, Beijing, China

5 School of Water Resources and Environment, China University of Geosciences, Beijing, China
Wackernagel. The theory is used for estimating the need of ecological productive space area sizes which sustain human natural resource consumption and assimilate the wastes arising from the human, and comparing with the ECC of a given area, through the ecological surplus and deficit (S\&D) to measure the sustainable development. Water resource is the natural resource which has the economic value and social value. It has an irreplaceable position in the process of social production and can maintain the ecological environment $(\mathrm{Lu}$ 2010). However, Wackernagel shrinks the range of water for using in the calculation, ignoring the estimates of the ecological footprint of water resources. The concept of water resources $\mathrm{EF}$ (WEF) is produced on the basis of the concept of EF, referring to any known population (a person, a city or a region) which needs the land of water resources for consuming products and services during a certain period of time (Hoekstra et al. 2003).The WEF is used to describe the ecological environment and social economic function of water, in order to make up for the inadequate description of water 
resources function (Ayres R U 2000). The WEF is different from water footprint which is proposed by A.Y. Hoekstra in 2003. The water footprint is an indicator for measuring using water, which is the amount of water needed for any product or service consumed in any given area (region or population) over a period of time, including direct and indirect water used by consumer or producer. In recent years, the shortage of water resources affected the sustainable development of the world social and economic environment seriously (Aall et al. 2005). The EF of water resources has become a hot study (Van et al. 2000; Simmons C et al. 2000; Niccolucci $\mathrm{V}$ et al. 2012). The EF model has the clear conceptual framework, simple operation and facilitate comparison between different regions (Bastianoni, et al. 2012). The EF method tries to use specific observable indicators to define sustainability, establishing a comprehensive account to compare the human ecological demand and ECC, monitoring the natural resource depletion caused by human needs, and exploring the way of sustainable development (Wackernagel and Galli 2007). The method has been widely used in many countries and regions (Wu et al. 2006). Luck et al. 2001 calculate the EF of food and water in 20 metropolitan area of American according to the city channel model and the EF method of spatial heterogeneity; Jenerette (2006) used the spatial heterogeneity of the EF method to calculate the EF of 33 urban of the United States and China, and analyzed the influencing factors. Fan (2010) analyzed the EF in the north of Shanxi in 2010, and studied the sustainable development situation of the ecological environment; Fangling Sun studied the EF of water resources in Shandong province (Sun. 2011). Therefore, this paper argues that EF model of water resources combines the natural attribute, social attribute and spatial properties, which can be defined as the ability of sustainable development, and the largest water supply is available to support the regional resources, environment and social ecological, the production and life at a specific historical stage of development in an area.

The water resources ECC in the international research results is relatively small, mainly around a specific area (Gerbens et al. 2009), combined input-output model with the EF model) for study (Hubacek et al. 2009. In addition, Faxing Du etc. (2009) built the water resources carrying capacity evaluation model based on attribute identification of entropy weight and traditional multi-objective analysis decision technology. This paper proposes the ecological carrying capacity model of water resources (ECC) which is based on the ecological footprint model. Compared with the previous definition of water resources carrying capacity, the ecological footprint method extends the meaning and content of the original definition with natural attributes, social attributes and spatial attributes. It emphasizes that water resource carrying capacity is the supportive capacity of water resources for the sound development of social systems and ecosystems. It not only emphasizes the needs of natural systems, but also focuses on the coordination within the economic system, and emphasizes the impact of time factors on water resources carrying capacity. The water resources carrying capacity is not only determined by the natural system, but also depends on the degree of economic and social development during the evaluation period. The ECC of water resources can be defined as the ability to support the sustainable development of resources, environment and social ecology, production and life in a particular historical stage of development in a particular region.

However, the previous literatures mainly discuss the issue of water resources EF from regional level. There is little in-depth research of the water resource EF in China. Recent studies only focus on the reproduction and consumption according to WEF in different areas and do not consider the different watershed scale. In the traditional EF model, the ECC model is not been included. The paper combines the EF and ECC model together for estimating the sustainability. Thus, the assessment is performed in city scale, basin scale and the whole province. A recent study on WEF presented the statistics of the sustainability of water resources on the basis of past and current water consumption. However, WEF is closely related to ECC. The ECC affects the water resource consumption particularly when consumption is regarded as constant. Therefore, most recent related studies maybe arbitrary for the sustainable assessment result based on WEF statistics. In our study, ECC is also considered in different scale for sustainable assessment to ensure that the WEF result of the water resource management and plan is available and reliable. The multi-scale dynamic analysis is introduced into the EF model which can calculate and analyze the EF and ECC from the city to secondary area basin and the provincial water resources.

Heilongjiang Province is a big province of grain, where the water resource is very important. Along with the rapid development of social economy, increasing population and accelerated urbanization process, water consumption of Heilongjiang continues to grow, and emissions of waste water are also increasing. The pressure of water resources and water environment are hard. The new method provides a basis for evaluation of sustainable development, realizing the sustainable utilization and management of water resources, which has a certain practical significance in Heilongjiang Province.

\section{Study site and methodology}

\section{Study site}

Heilongjiang Province is $473000 \mathrm{~km}^{2}$, which contains Harbin, Qiqihar, Jixi, Hegang, Shuang yashan, Daqing, 


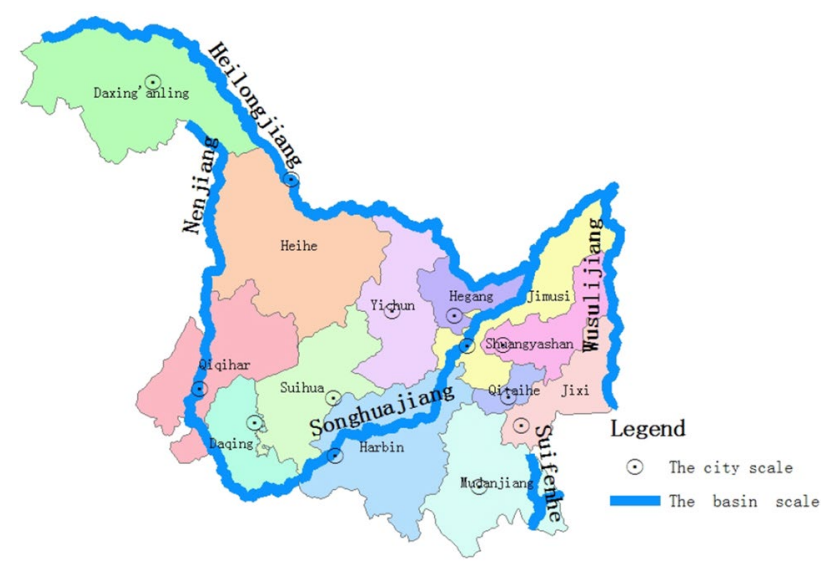

Fig. 1 Study area

Yichun, Jiamusi, Qitaihe, Mudanjiang, Heihe, Suihua and Daxing' anling, a total of 13 cities. There are Heilongjiang, Songhua river, Nenjiang river, Wusuli river and Suifenhe river five water system, as shown in Fig. 1. The average surface water resource of the whole province is 68.608 billion $\mathrm{m}^{3}$, and the average groundwater resource is 28.687 billion $\mathrm{m}^{3}$. Deducting the repeated computation of 16.262 billion $\mathrm{m}^{3}$, the average total water resources of the whole province is 81.033 billion $\mathrm{m}^{3}$, which are below the national average. Due to the influence of the geographical position and the development level of regional economy, the development and utilization level of water resources of Heilongjiang Province is uneven in 13 cities (area).

Based on the multi-scale evaluation method framework of water resources in Heilongjiang Province, the paper has built an in-depth comprehensive study, in order to apply the method of EF of water resources at multi-angle, all-round, dynamically. The specific technical route is shown in Fig. 2.

There are three scales for evaluating the water resources. The ecological footprint and ecological carrying capacity of Heilongjiang Province can be analyzed from three scales, but the difference is that the scope of the analysis is not the same.
From the local to the whole province, the water resources situation in Heilongjiang Province can be dynamically and comprehensively understood. The basic assessment is the city scale. The paper calculated the ECC of surfer water, groundwater and total water in every city of Heilongjiang Province, and then analyzed the spatial distribution difference of the ECC among the surface water, groundwater, and the overall. The water resource in these cities is relatively fixed, but the water resource is not static in the river system. Through the second scale, namely, the watershed scale, the paper analyzed the ecological S\&D, understanding the sustainable development situation of each basin. The third scale is the Heilongjiang Province; the paper calculated the ECC of the province and the correlation coefficient between ECC and the rainfall. Then the paper analyzed the trend of sustainable development through ecological S\&D, and different account percentage of $\mathrm{EF}$, understanding the specific usage of water resources.

\section{Water resource EF}

The water EF is the consumption of water resources which can be converted to the corresponding water area, and also can be converted into different accounts of water resources consumption in the region, using the water area for equalization, and comparing the equilibrium values in different regions worldwide. According to the characteristics and connotation of EF of water resources, connecting with the actual situation of the Heilongjiang Province, the water accounts can be divided into six categories - farmland irrigation, forestry fishing livestock, industrial, urban public, domestic and ecological water. The calculation model of water EF and the sub-accounts are calculated as follows (Huang 2008):

$\mathrm{EF}=N \times \mathrm{ef}=N \times \gamma_{\omega} \times\left[W / p_{\omega}\right]$,

where $\mathrm{EF}\left(\mathrm{hm}^{2}\right)$ is the water $\mathrm{EF}, N$ (capita) is the total population, ef ( $\mathrm{hm}^{2} /$ capita) is the water EF per capita, $\gamma_{w}$ is the equivalence factor of the water resource, $W\left(\mathrm{~m}^{3}\right)$ is the quantity of the water resource consumed by per capita, $P_{\omega}\left(\mathrm{m}^{3} / \mathrm{hm}^{2}\right)$ is the average yield for the water resource. The



Fig. 2 Process diagram of the method 
water $\mathrm{EF}$ is the sum of ecological production area of water consumption.

(1) Farmland irrigation water EF

$\mathrm{EF}_{\mathrm{f}}=N \times \mathrm{ef}_{\mathrm{f}}=N \times \gamma_{\omega} \times\left(W_{\mathrm{f}} / P_{\omega}\right)$,

where $\mathrm{EF}_{\mathrm{f}}\left(\mathrm{hm}^{2}\right)$ is the farmland irrigation WEF, $\mathrm{ef}_{\mathrm{f}}\left(\mathrm{hm}^{2} /\right.$ capita) is the farmland irrigation WEF per capita, $W_{\mathrm{f}}\left(\mathrm{m}^{3}\right)$ is the quantity of the water resource consumed in the farmland irrigation per capita.

(2) Forestry fishing livestock water EF

$\mathrm{EF}_{1}=N \times \mathrm{ef}_{1}=N \times \gamma_{\omega} \times\left(W_{1} / P_{\omega}\right)$,

where $\mathrm{EF}_{1}\left(\mathrm{hm}^{2}\right)$ is the forestry fishing livestock water $\mathrm{EF}, \mathrm{ef}_{1}$ $\left(\mathrm{hm}^{2} /\right.$ capita) is the forestry fishing livestock WEF per capita, $W_{1}\left(\mathrm{~m}^{3}\right)$ is the quantity of the water resource consumed in the forestry fishing livestock per capita.

(3) Industrial water EF

$\mathrm{EF}_{\mathrm{i}}=N \times \mathrm{ef}_{\mathrm{i}}=N \times \gamma_{\omega} \times\left(W_{\mathrm{i}} / P_{\omega}\right)$,

where $\mathrm{EF}_{\mathrm{i}}\left(\mathrm{hm}^{2}\right)$ is the industrial WEF, ef $\mathrm{f}_{\mathrm{i}}\left(\mathrm{hm}^{2} /\right.$ capita) is the industrial WEF per capita; $W_{\mathrm{i}}(\mathrm{m} 3)$ is the quantity of the water resource consumed in the industry per capita.

(4) Urban public water EF

$\mathrm{EF}_{\mathrm{u}}=N \times \mathrm{ef}_{\mathrm{u}}=N \times \gamma_{\omega} \times\left(W_{\mathrm{u}} / P_{\omega}\right)$,

where $\mathrm{EF}_{\mathrm{u}}\left(\mathrm{hm}^{2}\right)$ is the urban public WEF, $\mathrm{ef}_{\mathrm{u}}\left(\mathrm{hm}^{2} /\right.$ capita) is the urban public WEF per capita; $W_{\mathrm{u}}(\mathrm{m} 3)$ is the quantity of the water resource consumed in the urban public per capita.

(5) Domestic water EF

$E F_{d}=N \times e f_{d}=N \times \gamma_{\omega} \times\left(\mathrm{W}_{d} / P_{\omega}\right)$, where $E F_{d}\left(\mathrm{hm}^{2}\right)$ is the domestic WEF, $e f_{d}$ ( $\mathrm{hm}^{2} /$ capita) is the domestic WEF per capita; $W_{d}(\mathrm{~m} 3)$ is the quantity of the water resource consumed in the domestic per capita.

(6) Ecological WEF

$\mathrm{EF}_{e}=N \times \mathrm{ef}_{\mathrm{e}}=N \times \gamma_{\omega} \times\left(W_{\mathrm{e}} / P_{\omega}\right)$,

where $\mathrm{EF}_{\mathrm{e}}\left(\mathrm{hm}^{2}\right)$ is the ecological WEF, $\mathrm{ef}_{\mathrm{e}}\left(\mathrm{hm}^{2} /\right.$ capita) is the ecological WEF per capita, and $W_{\mathrm{e}}\left(\mathrm{m}^{3}\right)$ is the quantity of the water resource consumed in ecological protection per capita.

\section{Water resource ECC}

The carrying capacity has the advantages of quantization and widely applied to the resources, environment and population research (Yue et al. 2006). The calculation of carrying capacity of water resources should consider the ecological environment and social production synthetically, due to the different land productivity of the similar biology between different regions, and each kind of biological productive land area cannot be directly compared. The yield factor is a parameter which can make the biological productive land area comparable. After determining the yield factors which are calculated based on the global ecological productive average, the national or regional water resources ECC can be calculated. At the same time, on the advice of the world commission on environment and development, ECC should be deducting $12 \%$ of the area as the ecological compensation for biodiversity conservation. Within the framework of the EF theory, the model of ECC of water is shown in formula (Wang et al. 2013):

$\mathrm{EC}_{\omega}=N \times \mathrm{ec}_{\omega}=(1-12 \%) \times \psi \times \gamma_{\omega} \times Q / p_{\omega}$,

where $\mathrm{EC}_{\omega}\left(\mathrm{hm}^{2}\right)$ is the total water resource $\mathrm{ECC}, \mathrm{ec}_{\omega}\left(\mathrm{hm}^{2} /\right.$ capita) is the water resources carrying capacity per capita, $\psi$ is the yield factor, $\mathrm{Q}\left(\mathrm{m}^{3}\right)$ is the total water resource quantity, and (1-12\%) is the compensatory coefficient of biodiversity according to the WCED.

The $\psi$ can be calculated as follows:

$\psi=\mathrm{p}_{i} / p_{\omega}$,

where $\mathrm{p}_{i}$ is the regional average runoff module.

\section{Water resource ecological S\&D}

Ecological S\&D are the difference between the ECC and EF. The EF of water resources measures the sustainable development of ecologic mainly through the ecological deficit and ecological surplus of water resources. It can be used to comprehensive judge whether the production and consumption activities of a country or a region can be within the range of load in the local ecosystem, in other words, whether the development state is sustainable.

Budget $=\mathrm{EC}_{\omega}-\mathrm{EF}_{\omega}$.

When the ecological capacity is less than the EF of water resources in a region, the Budget $<0$, stands for "ecological deficit of water resources", suggesting that the water supply cannot meet the demand of the development of the ecological environment; when the ecological capacity is greater than the EF of water resources in a region, the Budget $>0$, stands for "ecological surplus of water resources", suggesting that the water resources can not only guarantee the ecological environment be good, but also there is allowance which can satisfy the demand of water resource in the further. Budget $=0$ stands for the water resources are in the ecological balance.

\section{The coefficient of correlation between the rainfall and the ECC of water}

The correlation coefficient is the statistical analysis index of the related degree between variable indexes; the calculation formula is as follows: 


$$
r_{\mathrm{ER}}=\frac{\sum\left(\mathrm{EC}_{\omega}-\overline{\mathrm{EC}} \mathrm{W}\right)(\mathrm{RF}-\overline{\mathrm{RF}})}{\sqrt{\sum\left(\mathrm{EC}_{\omega}-\overline{\mathrm{EC}_{\mathrm{W}}}\right)^{2} \sqrt{\sum(\mathrm{RF}-\overline{\mathrm{RF}})^{2}}}}
$$

where $r_{\mathrm{ER}}, \mathrm{EC}_{\omega}, \overline{\mathrm{EC}_{\mathrm{W}}}, \mathrm{RF}, \overline{\mathrm{RF}}$, respectively, stand for the correlation coefficient of the ECC of water resources and the rainfall, ECC of water resources $\left(\mathrm{hm}^{2}\right)$, the average ECC of water resources $\left(\mathrm{hm}^{2}\right)$, the rainfall of each year $(\mathrm{mm})$, the average rainfall of each year $(\mathrm{mm})$.

\section{Results and analysis}

\section{Multi-scale WEF}

After constructing the WEF multi-scale framework and employing the hydrological and population data, we were able to quantify the WEF for each sector in city scale and assess the WEF in multi-scale. The volume of the water resource required to satisfy the need and the sustainability level of the water resource were also identified in the region. In the research, the calculation parameters mainly refer to Linnan Huang (Huang et al. 2008), etc.: the average water production capacity of the world is $3140 \mathrm{~m}^{3} . \mathrm{hm}^{-2}$; the water equilibrium factor of the global is 5. 19 .

\section{City scale}

The Heilongjiang Province has 13 cities (region).The distribution of the water resources is uneven in each region. According to the water production modules of cities in Heilongjiang Province from 2000 to 2011, the paper calculated the average water production module, and then calculate the water yield factors of each city (area) (Table 1). At last the paper calculated the ECC of surface water, groundwater and the overall water resources based on EF calculation formula for each city (area) (Table 2), then mapped the space difference diagram of the ECC of water resources of cities (area) in Heilongjiang Province from 2009 to 2011 using ArcGIS, as shown in Fig. 3.

Table 2 presents the decline trends of the surface water's ECC are greater in Qitaihe, Suihua and Heihe; the decline trends of groundwater's ECC are greater in Qitaihe, Daxinganling and Shuangyashan; the decreasing degree of the water resources' ECC is bigger in Qitaihe, Jixi and Heihe; the ECC of water resources are greater in Da xing'anling, Harbin, Mudanjiang and Yichun; the average water ECC of Da xing' anling is over 10 million $\mathrm{hm}^{2}$ from 2009 to 2011; the ECC of water resources are weak in Daqing and Qitaihe,

Table 1 The water yield factors of each city (area)

\begin{tabular}{|c|c|c|c|c|c|c|c|c|c|c|c|c|c|}
\hline City & Harbin & Qiqihar & Mudanjiang & Jiamusi & Suihua & Heihe & Daqing & Daxing'anling & Jixi & Shuangyashan & Yichun & Qitaihe & Hegang \\
\hline A & 19.04 & 8.41 & 21.2 & 11.98 & 11.42 & 12.86 & 7.04 & 17.53 & 13.79 & 12.34 & 22.06 & 10.11 & 21.16 \\
\hline B & 0.61 & 0.27 & 0.68 & 0.38 & 0.36 & 0.41 & 0.22 & 0.56 & 0.44 & 0.39 & 0.7 & 0.32 & 0.67 \\
\hline
\end{tabular}

$A$ is average runoff modulus, $B$ is water resources yield factor

Table 2 The ECC of surface water, groundwater and the overall water resources of cities

\begin{tabular}{|c|c|c|c|c|c|c|c|c|c|}
\hline & \multicolumn{3}{|c|}{ Surface water } & \multicolumn{3}{|c|}{ Groundwater } & \multicolumn{3}{|c|}{ Overall water } \\
\hline & 2009 & 2010 & 2011 & 2009 & 2010 & 2011 & 2009 & 2010 & 2011 \\
\hline Harbin & 1107.84 & 1189.33 & 657.55 & 389.36 & 368.28 & 340.77 & 1304.15 & 1374.88 & 803.41 \\
\hline Qiqihar & 76.42 & 43.20 & 55.57 & 146.37 & 119.47 & 115.89 & 180.49 & 126.65 & 143.23 \\
\hline Mudanjiang & 1051.58 & 1078.78 & 741.31 & 203.55 & 189.41 & 174.37 & 1064.05 & 1091.84 & 751.89 \\
\hline Jiamus & 224.24 & 236.62 & 124.75 & 144.26 & 141.61 & 104.52 & 315.38 & 329.25 & 191.74 \\
\hline Suihua & 207.83 & 148.45 & 96.35 & 175.21 & 155.20 & 142.01 & 342.09 & 266.89 & 209.03 \\
\hline Heihe & 700.60 & 455.20 & 324.89 & 235.26 & 193.93 & 173.48 & 805.97 & 539.82 & 414.17 \\
\hline Daqing & 10.66 & 8.86 & 8.96 & 55.97 & 46.53 & 50.78 & 51.62 & 42.40 & 48.16 \\
\hline Daxing'anling & 1335.02 & 999.19 & 930.77 & 273.68 & 237.11 & 135.86 & 1343.33 & 1010.51 & 941.11 \\
\hline Jixi & 236.99 & 251.39 & 113.34 & 81.34 & 71.10 & 52.93 & 264.64 & 278.33 & 133.25 \\
\hline Shuangyashan & 153.50 & 195.76 & 117.59 & 65.46 & 58.09 & 35.57 & 179.03 & 221.74 & 131.72 \\
\hline Yichun & 1182.19 & 820.64 & 707.63 & 220.74 & 197.12 & 171.76 & 1205.41 & 840.19 & 726.87 \\
\hline Qitaihe & 37.14 & 39.61 & 14.29 & 16.06 & 14.48 & 7.91 & 43.89 & 45.61 & 17.64 \\
\hline Hegang & 399.95 & 336.12 & 246.75 & 116.65 & 109.93 & 104.08 & 476.06 & 406.18 & 311.95 \\
\hline
\end{tabular}



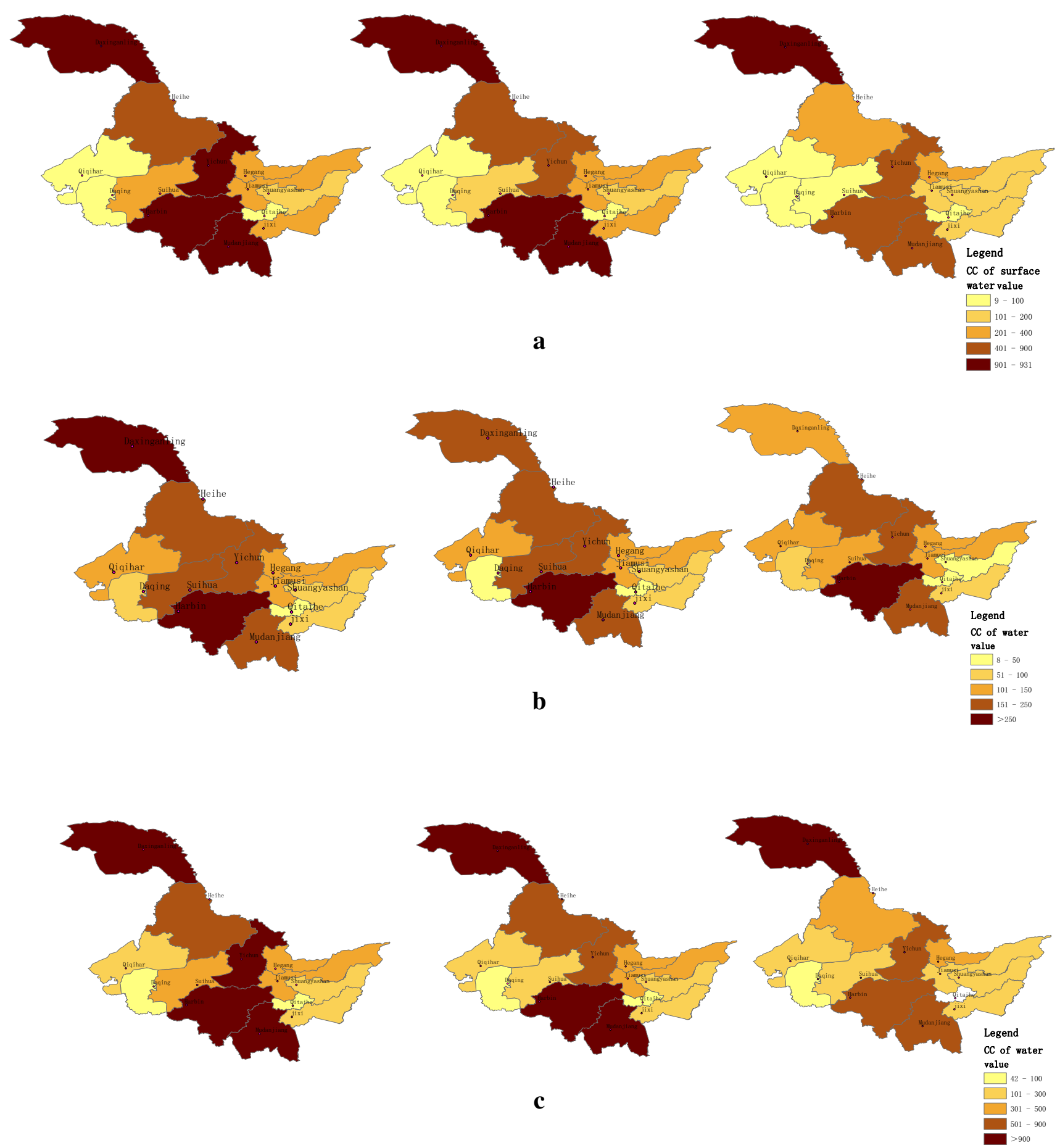

Fig. 3 Special distribution of water ECC about every city in Heilongiiang Province from 2009 to 2011. a The ECC of the surface water, $\mathbf{b}$ the $\mathrm{ECC}$ of the groundwater, $\mathbf{c}$ the ECC of the overall water

the average water ECC of Daqing is only under $500,000 \mathrm{hm}^{2}$ from $2009 \sim 2011$.

Figure 3 shows the space distribution of the water resources' carrying capacity is uneven in Heilongjiang Province. The northwest cities have abundant water resources where in the hill terrain, but because of sparsely populated, the water resources development level is not high, and the carrying capacity is strong. The water exploitation quantity of the cities increased in southeastern, and most cities are in the plain, where the food crop demand more water, and the carrying capacity is in the medium level; Daqing and Qitaihe belong to the heavy industry 
cities in Heilongiiang Province, with the increase of industrial wastewater emissions, which the carrying capacity of water resources value is low, and the carrying capacity is weak. Between 2009 and 2011, Qiqihar and Daqing's carrying capacity of groundwater resources are bigger than the surface water resources; Suihua's carrying capacity of groundwater resources is greater than surface water resources. In other cities, the carrying capacity of surface water resources is greater than the groundwater resources. The carrying capacity of surface water and groundwater resources are declining in each city, leading the reduction of the overall carrying capacity of water resources.

\section{Basin scale}

The water resources can be evaluated from the basin of secondary areas, which are the main entry and exit channel of water resources in Heilongjiang Province. The basins flow through different cities, so that we can analyze EF, ecological capacity and ecological "S\&D" of Heilongjiang Province from dynamic and a wide range of condition. According to the statistical data of water resources in Heilongjiang Province, the province mainly has five basins of secondary partition: Nenjiang, Heilongjiang, Songhuajiang, Wusulijiang and Suifenhe. First of all, according to the average runoff modulus of secondary partitions in $2000 \sim 2011$, the water yield factor of each basin can be calculated, (Table 3), then
Table 3 Water yield factor of each basin

\begin{tabular}{lllllr}
\hline Basin & Nenjiang & Songhuajiang & Heilongjiang & Wusulijiang & Suifenhe \\
\hline Average runoff modulus & 8.99 & 18.73 & 16.1 & 12.54 & 16.39 \\
Water resources yield factor & 0.29 & 0.60 & 0.51 & 0.40 & 0.52 \\
\hline
\end{tabular}

Table 4 Water ECC, EF and S\&D of each Basin

\begin{tabular}{|c|c|c|c|c|c|c|c|c|c|}
\hline \multirow[t]{2}{*}{ Year } & \multicolumn{3}{|c|}{ Nenjiang } & \multicolumn{3}{|c|}{ Songhuajiang } & \multicolumn{3}{|c|}{ Heilongjiang } \\
\hline & ECC & $\mathrm{EF}$ & S\&D & $\mathrm{ECC}$ & $\mathrm{EF}$ & S\&D & ECC & $\mathrm{EF}$ & S\&D \\
\hline 2000 & 238.53 & 1058.00 & -819.47 & 2498.23 & 2501.94 & -3.71 & 1335.92 & 316.85 & 1019.06 \\
\hline 2001 & 242.84 & 952.38 & -709.54 & 2188.07 & 2351.70 & -163.63 & 1472.86 & 306.28 & 1166.58 \\
\hline 2002 & 262.45 & 774.37 & -511.92 & 2939.30 & 2030.22 & 909.08 & 936.53 & 304.95 & 631.58 \\
\hline 2003 & 691.94 & 986.60 & -294.66 & 2958.32 & 1823.94 & 1134.39 & 1976.47 & 267.43 & 1709.04 \\
\hline 2004 & 385.41 & 1027.59 & -642.18 & 2306.23 & 1940.80 & 365.44 & 1611.28 & 270.41 & 1340.87 \\
\hline 2005 & 433.16 & 1076.02 & -642.86 & 3451.06 & 2011.21 & 1439.85 & 1243.34 & 289.91 & 953.43 \\
\hline 2006 & 461.46 & 1065.11 & -603.65 & 2682.72 & 2105.75 & 576.97 & 1581.53 & 312.39 & 1269.14 \\
\hline 2007 & 268.65 & 1040.31 & -771.66 & 1927.04 & 1985.59 & -58.55 & 858.49 & 386.27 & 472.22 \\
\hline 2008 & 295.01 & 1035.52 & -740.51 & 1882.09 & 2145.42 & -263.33 & 806.05 & 372.39 & 433.66 \\
\hline 2009 & 538.02 & 1072.88 & -534.85 & 4231.35 & 2316.49 & 1914.86 & 2060.07 & 399.99 & 1660.08 \\
\hline 2010 & 391.06 & 1064.94 & -673.88 & 3847.62 & 2337.32 & 1510.30 & 1515.36 & 437.68 & 1077.68 \\
\hline 2011 & 349.01 & 1223.62 & -874.61 & 2569.71 & 2655.16 & -85.46 & 1373.75 & 495.36 & 878.39 \\
\hline \multirow[t]{2}{*}{ Year } & \multicolumn{3}{|c|}{ Wusulijiang } & & & \multicolumn{4}{|c|}{ Suifenhe } \\
\hline & \multicolumn{2}{|c|}{ ECC } & $\mathrm{EF}$ & \multicolumn{2}{|c|}{$S \& D$} & ECC & \multicolumn{2}{|r|}{ EF } & $S \& D$ \\
\hline 2000 & \multicolumn{2}{|c|}{466.44} & 995.69 & \multicolumn{2}{|c|}{-529.25} & 126.24 & \multicolumn{2}{|r|}{32.40} & 93.84 \\
\hline 2001 & \multicolumn{2}{|c|}{450.03} & 1111.06 & \multicolumn{2}{|c|}{-661.03} & 94.70 & \multicolumn{2}{|r|}{31.07} & 63.62 \\
\hline 2002 & \multicolumn{2}{|c|}{518.74} & 1032.71 & \multicolumn{2}{|c|}{-513.97} & 137.58 & \multicolumn{2}{|r|}{27.60} & 109.98 \\
\hline 2003 & \multicolumn{2}{|c|}{299.22} & 946.60 & \multicolumn{2}{|c|}{-647.37} & 44.70 & \multicolumn{2}{|r|}{38.35} & 6.35 \\
\hline 2004 & \multicolumn{2}{|c|}{394.35} & 1006.26 & \multicolumn{2}{|c|}{-611.91} & 87.13 & \multicolumn{2}{|r|}{43.14} & 43.99 \\
\hline 2005 & \multicolumn{2}{|c|}{388.18} & 1068.58 & \multicolumn{2}{|c|}{-680.40} & 89.33 & \multicolumn{2}{|r|}{41.98} & 47.34 \\
\hline 2006 & \multicolumn{2}{|c|}{501.34} & 1197.67 & \multicolumn{2}{|c|}{-696.32} & 88.95 & & 49.92 & 39.03 \\
\hline 2007 & & & 1358.16 & & .83 & 88.04 & & 45.62 & 42.42 \\
\hline 2008 & & & 1322.79 & & .95 & 77.98 & & 33.06 & 44.92 \\
\hline 2009 & & & 1405.10 & & .91 & 82.67 & & 32.73 & 49.94 \\
\hline 2010 & & & 1494.19 & & .21 & 130.92 & & 37.69 & 93.24 \\
\hline 2011 & & & 1436.84 & & 0.56 & 83.35 & & 13.06 & 70.29 \\
\hline
\end{tabular}


the corresponding numerical results can be calculate, which are shown in Table 4 according to the EF method.

Table 4 presents the results; the ECC of Nenjiang basin increased gradually before 2003, and it achieved at the highest (6.9194 million $\mathrm{hm}^{2}$ ) at 2003. The EF of Nenjiang basin changes little, which floating up and down at 10 million $\mathrm{hm}^{2}$ from 2000 to 2011; because the EF is greater than the ECC, the Nenjiang basin is in a state of ecological deficit of water resources, and present the approximate direction with ECC.

The EF of main stream of Songhuajiang basin is higher, which is more than 15 million $\mathrm{hm}^{2}$. The ECC reached the highest at 2009, which is 42.31 million $\mathrm{hm}^{2}$. The EF was floating at 19-27 million $\mathrm{hm}^{2}$, fluctuating in a downward trend from 2000 to 2003, which was the lowest of 18.2394 million $\mathrm{hm}^{2}$ at 2003, then it was on the rise. The main stream of Songhuajiang basin was in ecological deficit at 2000, 2001, 2007, 2001, 2011, and the general trend was the same as the ECC.

The ECC of main stream of Heilongjiang basin reached the highest value of 20.6007 million $\mathrm{hm}^{2}$ at 2009 , due to the Heilongjiang basin flows through many cities, whose carrying capacity changed volatile. The EF was between 2.6743 and 4.9536 million $\mathrm{hm}^{2}$, and declined from 2000 to 2003, rising from 2003 to 2011, which the overall volatility is flat. Because the ECC was greater than the EF, the Heilongjiang basin was in the ecological surplus state, and the overall trend was like the ECC.

The ECC of Wusuli basin changed little, which was about 5 million $\mathrm{hm}^{2}$ from 2000 to 2011; the EF is greater than the ECC, which was gradually rising after 2003, and reached the peak of 14.9419 million $\mathrm{hm}^{2}$ at 2010. Wusulijiang basin was in a state of ecological deficit and changed gradually serious, and the ecological deficit was -11.11 million $\mathrm{hm}^{2}$ in 2011 .

The ecologic carrying capacity of Suifenhe basin reached the lowest at 2003, which was $447,000 \mathrm{hm}^{2}$, then increased; it changed little from 2004 to 2009, and reached at 1.3092 million $\mathrm{hm}^{2}$ at 2010 , then fell to about $833,500 \mathrm{hm}^{2}$. The EF fluctuated at $276,000 \mathrm{hm}^{2} \sim 499,200 \mathrm{hm}^{2}$ slightly during 2000-2010, which was the lowest of $130,600 \mathrm{hm}^{2}$ at 2011; the Suifenhe basin was in the ecological surplus state, due to the ECC was low in 2003, and the ecological surplus value was low of $63500 \mathrm{hm}^{2}$. The overall trend was like the ECC.

For transverse comparison the EF, ECC and ecological S\&D of each basin, Fig. 4 shows the EF value of trunk stream of Songhua basin is the biggest; the Suifenhe basin is the minimum; the second is the Heilongjiang basin; the EF of Nenjiang and Wusulijiang basin is similar; the ECC of trunk stream of Songhuajiang and Heilongjiang are larger, and the change is volatile; the remaining three basins are small, and the change floating is small, which was below 10 million $\mathrm{hm}^{2}$. The differences of the
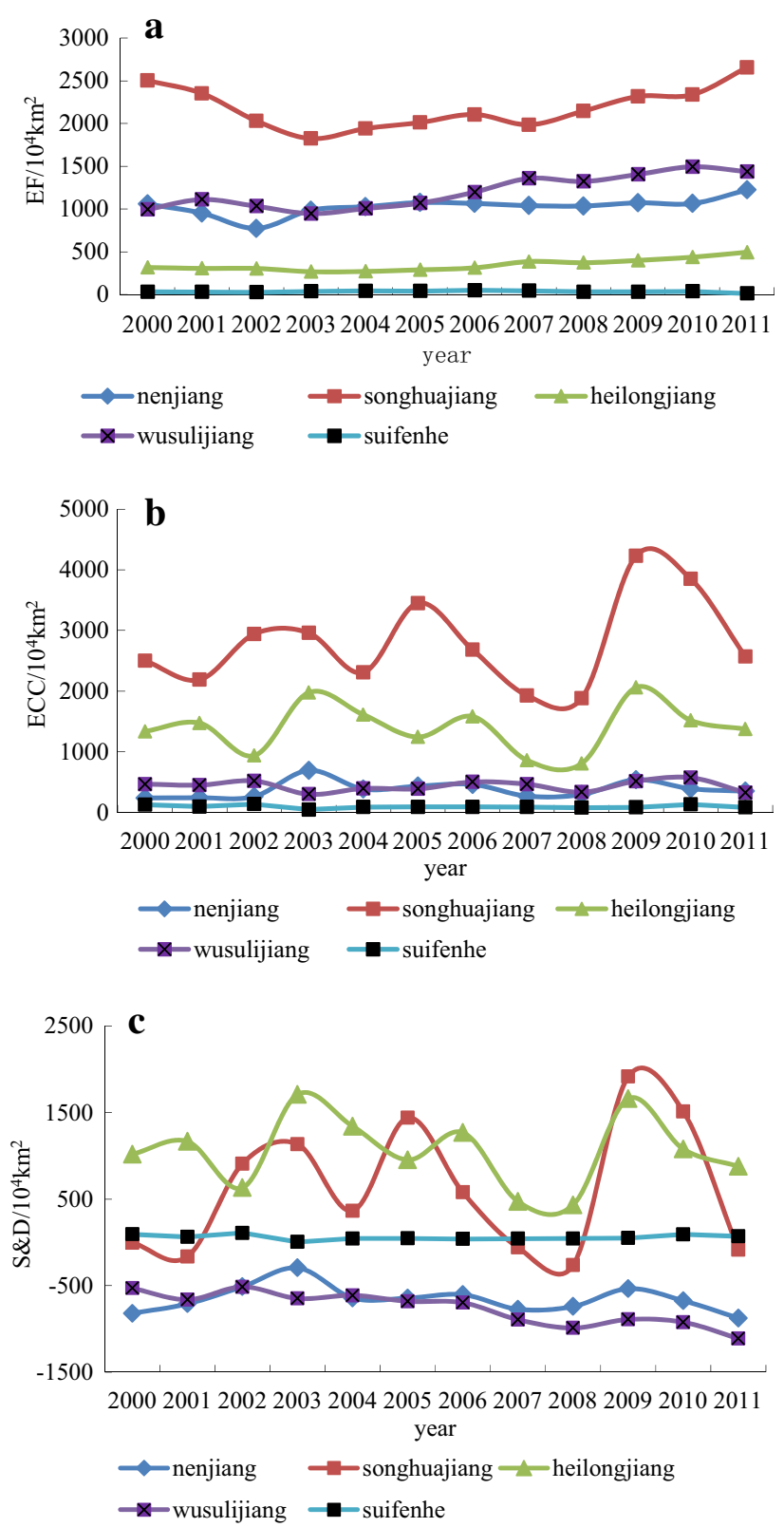

Fig. 4 Comparisons of water EF, ECC and S\&D about each basin. a The water EF of each basin, $\mathbf{b}$ the water ECC of each basin, $\mathbf{c}$ the water $\mathrm{S} \& \mathrm{D}$ of each basin

ecological S\&D of each basin are bigger; the ecological surplus of Heilongjiang basin is good; the trunk stream of Songhua basin is in the ecological deficit during part of the years; Suifenhe was in the ecological surplus all for the years, which was in the medium level; the ecological slurps and deficit situation of Nenjiang and Wusulijiang basin was bad, which were all in the ecological deficit, and it was visible that the trunk of Suifenhe, Heilongjiang basin and the Songhuajiang basin were in the sustainable 
development state; the Nenjiang and Wusulijiang basin were in unsustainable development state.

\section{Province scale}

On the basis of analysis of each city and basin of secondary partition, the paper analyzed the water resources of whole province of Heilongjiang. According to the index data of the water resources in Heilongjiang Province from 2000 to 2011, the water yield factor of Heilongjiang through many years was calculated, which is 0.48 ; then according to the calculation model of this paper, the EF and ECC of the water resources of Heilongjiang Province are calculated, drawing in Fig. 5. We can see that the EF of the water resources in Heilongjiang Province was gradually reducing during
$2000 \sim 2003$, and the lowest was 40.6291 million $\mathrm{hm}^{2}$. After the 2003, the EF increased year by year, and the EF reached the peak of 58.2404 million $\mathrm{hm}^{2}$ in 2011; the ECC of water resources in Heilongjiang Province changed erratically, and the ECC was higher in 2003, then the downward trend was presented, but the level of ECC reached the highest of 69.0903 million $\mathrm{hm}^{2}$ in 2009; the next 2 years was declining. The ECC of water resources and the rainfall have an observably proportional relationship of each year in Heilongjiang Province, as shown in Fig. 6. The correlation coefficient is 0.89 . The relationship between EF and ECC of water resources can be shown by the ecological surplus (deficit) which can be seen from Fig. 7. The Heilongjiang Province was in a state of ecological deficit in 2000, 2001, 2007, 2008 and 2011, and the ecological surplus situation was
Fig. $5 \mathrm{EF}$ and ECC of water in Heilongjiang
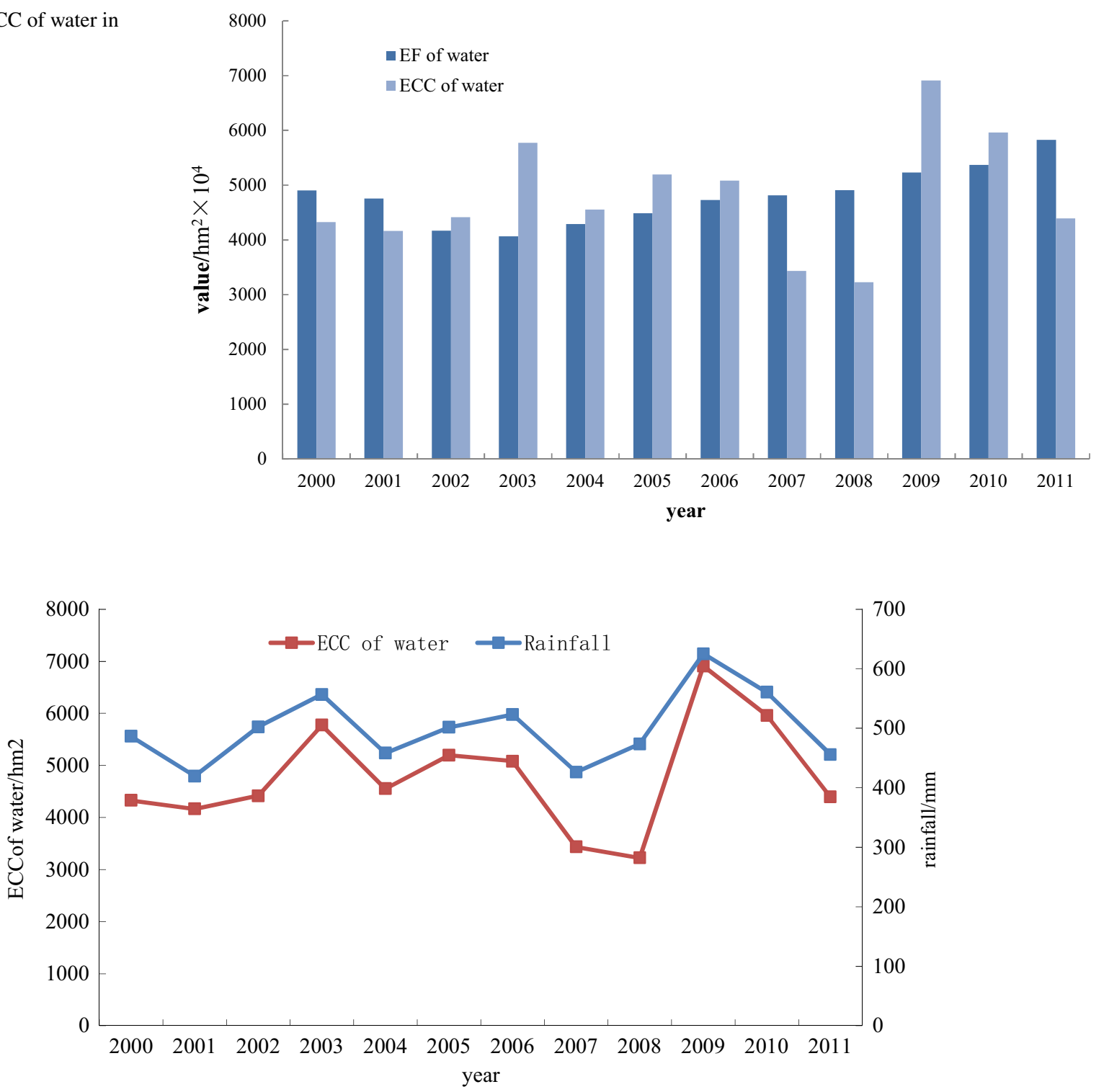

Fig. 6 Relation between the ECC and the rainfall 


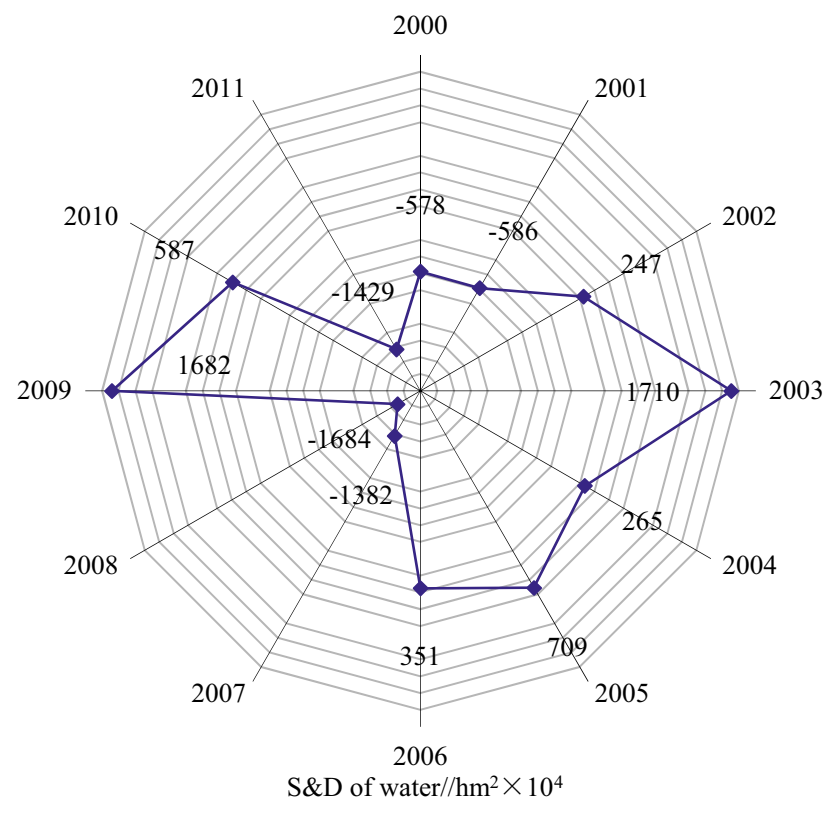

Fig. 7 Ecological surplus (deficit) in Heilongjiang

prominent in 2003 and 2009. The ecological surplus value was 16.82 million $\mathrm{hm}^{2}$ in 2009, and others were between $0 \sim 10$ million $\mathrm{hm}^{2}$ during the years.

The EF account of water resources in Heilongjiang Province consists of farmland irrigation, forestry fishing livestock, industrial water, urban public, domestic water and ecological water six parts. The paper calculated the EF of each part by EF model, and mapped the proportion of each account in all the accounts. As shown in Fig. 8, the figure presents the irrigation account is the main part, and the percentage is an upward trend which was more than $70 \%$ in 2011. The account of forestry fishing livestock has a little proportions, which is all below 7\%; the percentage of the industrial water account is gradually declining from 2000 to 2011, which fell from 32 to $12 \%$. The proportions of urban public and ecological water accounts are less, which are around $1 \%$; the proportions of domestic water account are uniform in each year, which are around 5\%.

\section{Discussion}

\section{The space difference of the ECC of water resources in Heilongjiang Province}

The spatial differences of ECC of water resources are big in Heilongjiang Province. The ECC is largest in Daxing' anling, because the water resource is abundant and the precipitation is more, but the population is small. The utilization of water resources is low, but the water ECC is bigger. The water ECC decreased significantly in western and eastern, and the water resources are relatively small in the regions where the consumption of water is mainly used on agricultural production. Daqing is an industry city where the development and utilization of water resources are higher, so the ECC level is lower.
Fig. 8 EF accounts of water resources in Heilongjiang Province

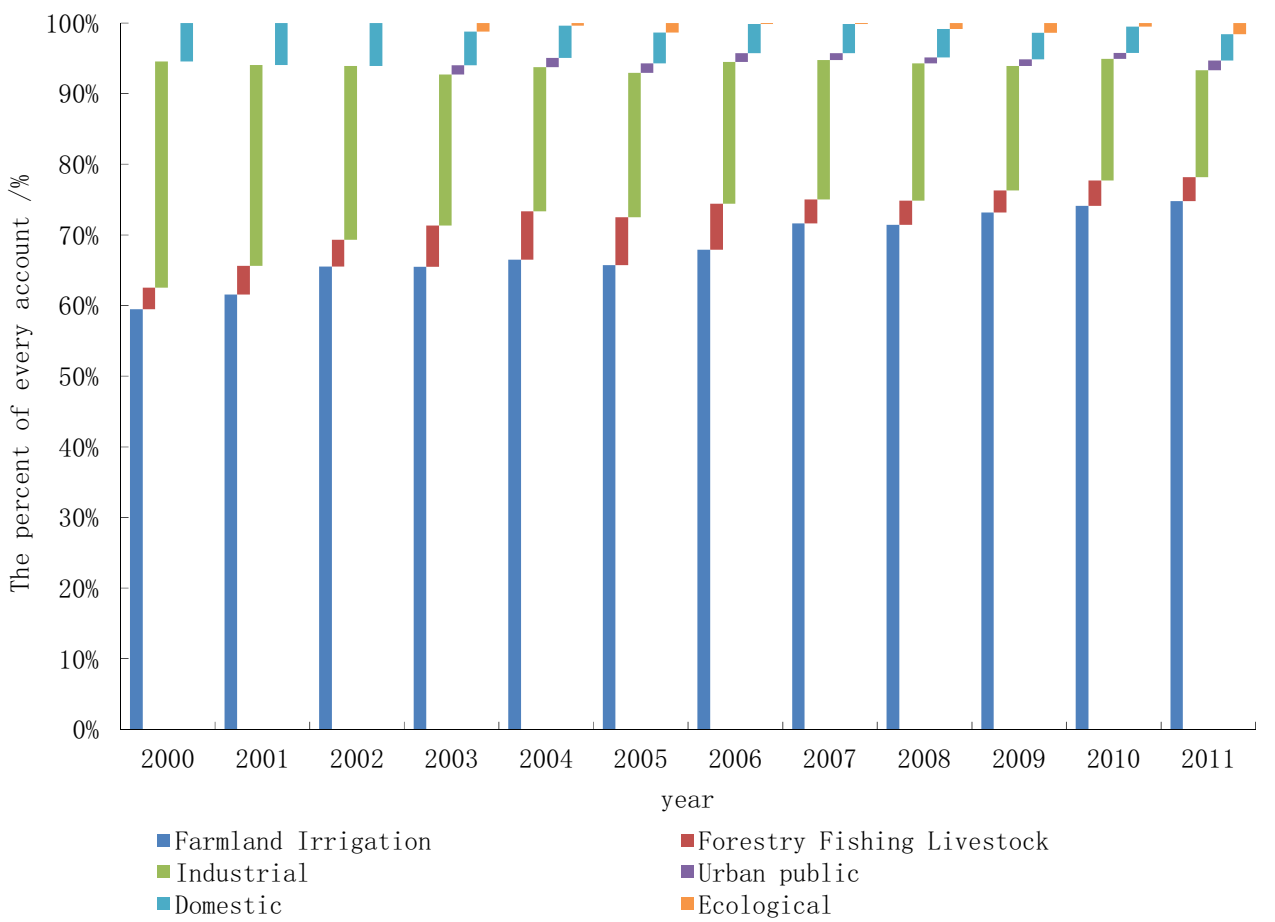




\section{The relation between the EF of basin and the geographic location in Heilongjiang Province}

During 2000-2011, the gap of the EF of five big basin in Heilongjiang Province is large The EF of trunk stream of Songhua basin is around 20 million $\mathrm{hm}^{2}$; the Wusuli basin is from $1000 \mathrm{hm}^{2}$ to $1500 \mathrm{hm}^{2}$; the Nenjiang basin is around 10 million $\mathrm{hm}^{2}$; the Heilongiiang basin is under 5 million $\mathrm{hm}^{2}$, while the Suifenhe basin is under $500,000 \mathrm{hm}^{2}$, which was related with the location of each river basin. The Songhuajiang flows through the main industrial city of Harbin, Jiamusi where the demand of water is bigger, so the value of EF is higher. Suifenhe is mainly in Mudanjiang where the demand of water is relative less, so the EF value is lower.

\section{The relation between the ECC of water resources and the precipitation in Heilongjiang Province}

The water resources mainly come from the precipitation in Heilongjiang Province. The ECC of water resources and the historical precipitation have the positive relationship which the ECC of water resources is decreased obviously during the low precipitation years. In this study, the years of 2000 and 2001 are dry in Heilongjiang Province, recovering from 2002 to 2003, 2004-2009 gradually. The precipitation in 2003 and 2009 are more which belong to the wet year, so the ECC is larger and the ecological surplus value is higher when they appeared in the analysis of the above two prominent years of 2003 and 2009.

\section{The relation between the EF of water and the economic development of social in Heilongjiang Province}

The carrying capacity of water resources is an important index of water resources security, whose size is one of the conditions of social and economic development (Duro 2013). According to the connotation of water resources' EF, the greater demand of water resources for social development, the per capita EF of water resources is higher (Ferng 2014). As a big agricultural province, the Heilongjiang Province is given priority to agricultural production, and the economic development is relatively backward, leading to the demand for water resources being less than the economically developed areas. But with the development of economy, the increasing demand for water resources, the EF of water resources showed a rising trend in Heilongjiang Province from 2000 to 2011. The contradiction between economic development of social and water resources will be more and more prominent. Heilongjiang Province is a big agricultural province where the EF of farmland irrigation water is more than $55 \%$ of the province's $\mathrm{EF}$, which is related to the improving grain production of Heilongjiang Province in recent years.

\section{Conclusions}

In this paper, the multi-scale EF model of water resources evaluation of Heilongjiang Province is presented, respectively, from the surface water, groundwater, overall ECC of each city (area) to the EF, ECC and ecological S\&D of each basin, and the ECC, EF, and ecological S\&D of entire province. The paper calculated the ECC, the EF and ecological S\&D of water resources of Heilongjiang Province from 2000 to 2011, drawing the corresponding conclusions.

(1) From the overall, the water resource is rich in Heilongjiang Province, but the EF of water is increasing. The year of low ECC of water resources has emerged ecological deficit, just like 2000, 2001, 2007, 2008 and 2011, when the utilization of water resource was in an unsustainable development state in Heilongjiang Province.

(2) The water space of the development and utilization are large in Heilongjiang Province, but the space distribution of water resources is extremely uneven. The ECC of water in hill areas of northern is strong. In the southwest, the economy is more developed, and the carrying capacity is low, especially in Qiqihaer, Suihua, and Daqing. They should adjust the structure of industry, controlling the water consumption and serious polluting enterprises. The southeast regions belong to the plain region should adjust the planting structure of grain, reducing the planting scale of crops which use more water but the quality is low. From the distribution of EF account of water resources in Heilongjiang Province, it presents that the structure of industry should be adapted to the ECC of each city in Heilongjiang Province.

(3) The water resources mainly come from the precipitation in Heilongjiang Province, and it is associated with the carrying capacity. In dry years, the carrying capacity of water resources is reduced, leading to the ecological surplus decrease and affecting the sustainable utilization of water resources.

Acknowledgements This research has been supported by funds from national natural science foundation of China (51709273); National Key R\&D Program of China (2017YFC0406004). 


\section{Compliance with ethical standards}

Conflict of interest The authors declare that they have no conflict of interest.

Open Access This article is distributed under the terms of the Creative Commons Attribution 4.0 International License (http://creativecomm ons.org/licenses/by/4.0/), which permits unrestricted use, distribution, and reproduction in any medium, provided you give appropriate credit to the original author(s) and the source, provide a link to the Creative Commons license, and indicate if changes were made.

\section{References}

Aall C, Høyer KG, Hall CM, Higham J (2005) Tourism and climate change adaptation: the norwegian case. Tourism Recreat Clim Change 40(1):434-435

Ayres RU (2000) commentary on the utility of the ecological footprint concept. Ecol Econ 32(3):347-349

Bastianoni S, Niccolucci V, Pulselli RM, Marchettini N (2012) Indicator and indicandum: "sustainable way" vs, "prevailing conditions" in the ecological footprint. Ecol Indic 16:47-50

Duro JA, Teixidó-Figueras J (2013) Ecological footprint inequality across countries: the role of environment intensity, income and interaction effects. Ecol Econ 93(3):34-41

Fan H (2010) Based on the theory of the ef of northern shanbei ecological environment sustainable development research. $\mathrm{PhD}$ Thesis. Beijing Forestry University, Beijing

Fa-Xing DU, Cao GJ, Liang C, Liu DF (2009) Attribute recognition model on entropy to comprehensively evaluate water resources bearing capacity. J Harbin Inst Technol 41(11):243-244

Ferng JJ (2014) Nested open systems: an important concept for applying ecological footprint analysis to sustainable development assessment. Ecol Econ 106(7):105-111

Gerbensleenes PW, Hoekstra AY, Meer TVD (2009) The water footprint of energy from biomass: a quantitative assessment and consequences of an increasing share of bio-energy in energy supply. Ecol Econ 68(4):1052-1060

Hoekstra AY (2003) Water scarcity in the zambezi basin in the longterm future: a risk assessment. Integrt Ass 4(3):185-204
Huang LN, Zhang WX, Jiang CL, Fan XQ (2008) Ecological footprint method in water resources assessment. Acta Ecologica Sinica 28(3):1279-1286

Hubacek K, Guan D, Barrett J, Wiedmann T (2009) Environmental implications of urbanization and lifestyle change in china: ecological and water footprints. J Clean Prod 17(14):1241-1248

Jenerette GD, Wu W, Goldsmith S, Marussich WA, Roach WJ (2006) Contrasting water footprints of cities in china and the united states. Ecol Econ 57(3):346-358

Luck MA, Jenerette GD, Wu J, Grimm NB (2001) The urban funnel model and the spatially heterogeneous ecological footprint. Ecosystems 4(8):782-796

Niccolucci V, Tiezzi E, Pulselli FM, Capineri C (2012) Biocapacity vs, ecological footprint of world regions: a geopolitical interpretation. Ecol Indic 16(5):23-30

Lu Q (2010) Mechanism of water cycle under system of environmentaleconomic accounting for water. J Econ W Resour 4:003

Rees WE (1992) Ecological footprints and appropriated carrying capacity: what urban economics leaves out. Focus 6(2):121-130

Simmons C (2000) Two feet-two approaches: a component based model of ecological footprinting. Ecol Econ 32(3):375-380

Sun F (2011) Study on the water resources ecological footprint in Shandong Province. PhD Thesis. Shandong Normal University, Jinan

Wackernagel M, Galli A (2007) An overview on ecological footprint and sustainable development: a chat with Mathis Wackernagel. Int J Ecodyn 2(1):1-9

Wang S, Yang FL, Xu L, Du J (2013) Multi-scale analysis of the water resources carrying capacity of the liaohe basin based on ecological footprints. J Clean Prod 53(16):158-166

Wu LJ, Yang L, Su X (2006) Advances in ecological footprint. J China Agric Univ

Yue D, Xu X, Li Z, Hui C, Li W, Yang H et al (2006) Spatiotemporal analysis of ecological footprint and biological capacity of Gansu, china 1991-2015: down from the environmental cliff. Ecol Econ 58(2):393-406

Publisher's Note Springer nature remains neutral with regard to jurisdictional claims in published maps and institutional affiliations. 